\title{
Conflitos causados pela predação de rebanhos domésticos por grandes felinos em comunidades quilombolas na Mata Atlântica
}

\author{
Francesca Belem Lopes Palmeira ${ }^{1,3}$ \& Walter Barrella ${ }^{2}$
}

Biota Neotropica v7 (n1) - http://www.biotaneotropica.org.br/v7n1/pt/abstract?article+bn03707012007

\author{
Recebido em 20/06/06 \\ Versão reformulada recebida em 06/02/07 \\ Publicado em 31/03/07
}

\author{
${ }^{I}$ Departamento de Pesquisa, Reserva Brasil, Avenida Dr. Silva Melo, 520, apto. 606, \\ Jardim Taquaral, CEP 04675-010, São Paulo, SP, Brasil \\ ${ }^{2}$ Departamento de Ciências do Ambiente, Faculdade de Ciências Biológicas, Centro de Ciências Médicas e \\ Biológicas, Pontifícia Universidade Católica de São Paulo, Praça José Ermírio de Moraes, 290, \\ Jardim Vergueiro, CEP 18030-095, CP 1570, Sorocaba, SP, Brasil, http://www.sorocaba.pucsp.br \\ ${ }^{3}$ Autor para correspondência: Francesca Belem Lopes Palmeira, e-mail: yagouaroundi@yahoo.com.br, \\ http://www.reservabrasil.org.br
}

\section{Abstract}

Palmeira, F.B.L. \& Barrella, W. Conflicts caused by predation on domestic livestock by large cats in quilombola communities in the Atlantic Forest. Biota Neotrop. Jan/Apr 2007 vol. 7, no. 1 http://www.biotaneotropica.org.br/v7n1/pt/abstract?article+bn03707012007 ISSN 1676-0603.

Domestic livestock predation by jaguars (Panthera onca) and pumas (Puma concolor) was recorded from 1998 to 2000 and local opinion to solve the conflict was investigated in two quilombola communities in the Atlantic Forest. The householders were interviewed regularly from May 2000 to January 2001. Predation depended on the number of domestic animals per household, and was apparently selective and possibly seasonal. The economic damage was high when associated with the low livestock number. People's attitude towards predators was negative and most of those surveyed (54\%) suggested these animals should be eliminated. Knowing the local perception is essential to adopt a participative management to reduce household losses and to guarantee large cats' conservation.

Keywords: Atlantic Forest, human-wildlife conflict, Panthera onca, perception, Puma concolor.

\section{Resumo}

Palmeira, F.B.L. \& Barrella, W. Conflitos causados pela predação de rebanhos domésticos por grandes felinos em comunidades quilombolas na Mata Atlântica. Biota Neotrop. Jan/Apr 2007 vol. 7, no. 1 http://www.biotaneotropica.org.br/v7n1/pt/abstract?article+bn03707012007 ISSN 1676-0603.

A predação de rebanhos domésticos por onças-pintadas (Panthera onca) e onças-pardas (Puma concolor) foi quantificada de 1998 a 2000 e a opinião local para resolver o conflito foi investigada em duas comunidades quilombolas na Mata Atlântica. Os responsáveis pelas propriedades foram entrevistados regularmente de maio de 2000 a janeiro de 2001. A predação foi dependente do número de animais domésticos nas propriedades, foi aparentemente seletiva e possivelmente sazonal. O prejuízo econômico foi alto quando associado com o baixo número de criações. A população expressou uma visão bastante negativa frente à presença de onças e a maior parte $(54 \%)$ sugeriu o extermínio desses animais. Conhecer a percepção local é fundamental para adotar um planejamento participativo que reduza as perdas dos proprietários e garanta a conservação dos grandes felinos.

Palavras-chave: conflito homem-natureza, Mata Atlântica, Panthera onca, percepção, Puma concolor. 


\section{Introdução}

Os conflitos entre proprietários de criações domésticas e predadores, provavelmente, tiveram início desde que os primeiros animais foram domesticados pelos seres humanos há cerca de 9.000 anos (Nowell \& Jackson 1996). Em diversas partes do mundo proprietários têm seus rebanhos domésticos predados por tigres (Panthera tigris) (Seidensticker \& McDougal 1993), leões (Panthera leo) (Anderson 1981, Hemson 2003, Patterson et al. 2004), leopardos (Panthera pardus) (Mizutani 1993), leopardos-das-neves (Panthera uncia) (Schaller et al. 1988, Oli et al. 1994, Jackson \& Wangchuk 2001), entre outros.

Em regiões neotropicais, a predação de rebanhos domésticos por onças-pardas (Puma concolor) e onças-pintadas (Panthera onca) tem sido documentada na Venezuela (Hoogesteijn et al. 1993, Polisar et al. 2003), no Chile (Rau \& Jiménez 2002), na Argentina (Perovic \& Herrán 1998) e em Belize (Rabinowitz 1986). No Brasil, os primeiros registros da predação por onças ocorreram na década de quarenta, quando várias mulas foram atacadas durante as expedições científicas no Roncador-Xingu-Tapajós, Estado de Mato Grosso (Carvalho et al. 1949, Villas-Bôas \& Villas-Bôas 1995, Sick 1997). Recentemente, diversas pesquisas avaliaram a predação de rebanhos domésticos por onças em diferentes ecossistemas como o Pantanal (Zimmermann et al. 2005), o Cerrado (Palmeira 2004), a Floresta Amazônica (Michalski et al. 2006) e a Mata Atlântica (Rylands et al. 1995, Manzatti 1999, Mazzolli et al. 2002, Conforti \& Azevedo 2003).

Entre os ecossistemas brasileiros habitados por onças, a Mata Atlântica é o que mais sofreu processos de fragmentação. Atualmente, estima-se que restam cerca de 7\% da sua área original (Mittermeier et al. 1999). A conversão do hábitat vem sendo a maior ameaça para a população de onças-pintadas da Mata Atlântica (Sanderson et al. 1999). Em diversas áreas do Sudeste do Estado de São Paulo, as onças se deslocam entre as unidades de conservação e as propriedades particulares do entorno e, ocasionalmente, atacam animais domésticos. Apesar dessas propriedades estarem inseridas na Área de Proteção Ambiental (APA) da Serra do Mar, a perseguição a felinos ainda é freqüente (Guix 1997). A predação de criações domésticas por onças também ocorre nas comunidades Maria Rosa e Porto dos Pilões, remanescentes de quilombos localizados em uma das áreas mais preservadas de Mata Atlântica, no entorno dos Parques Estaduais Turístico do Alto Ribeira (PETAR) e Intervales. Os ataques causados por onças têm gerado um intenso conflito socioambiental devido à presença destes predadores nas proximidades das residências dos quilombolas. Diante de tal situação, esta pesquisa quantificou os animais domésticos atacados por onças de 1998 a 2000 e levantou a opinião dos quilombolas para resolver o conflito. Conhecer a percepção local é fundamental para adotar um planejamento participativo que reduza os danos dos quilombolas e garanta a conservação das onças.

\section{Material e Métodos}

\section{1. Área de estudo}

As comunidades Maria Rosa e Porto dos Pilões estão situadas entre as coordenadas geográficas $24^{\circ} 23^{\prime}$ a $24^{\circ} 31^{\prime} \mathrm{S}$ e $48^{\circ} 23^{\prime}$ a $48^{\circ}$ 32' W, Município de Iporanga, Vale do Ribeira, Sudeste do Estado de São Paulo, e apresentam áreas de 3.375 ha e 6.222 ha, respectivamente. A cobertura vegetal é classificada como Floresta Ombrófila Densa. A altitude varia de 80 a $900 \mathrm{~m}$ aproximadamente. O clima é classificado como clima tropical chuvoso de floresta, com temperaturas anuais variando de 18 a $22{ }^{\circ} \mathrm{C}$. A média anual de precipitação se encontra entre 1200 a 1500 mm (Melo \& Salaroli 1990, Fundação Florestal 1997).

A fauna de predadores é caracterizada pela presença de diversas espécies como jacaré-do-papo-amarelo (Caiman latirostris), gaviãopomba (Leucopternis polionota), gavião-pomba-grande (Leucopternis lacerlunata), gavião-de-penacho (Spizaetus ornatus), gavião-pegamacaco (Spizaetus tyrannus), lontra (Lontra longicaudis), mão-pelada (Procyon cancrivorus), cachorro-do-mato (Cerdocyon thous), gato-mourisco (Herpailurus yagouaroundi), gato-do-mato-pequeno (Leopardus tigrinus), gato-maracajá (Leopardus wiedii), jaguatirica (Leopardus pardalis), onça-parda (Puma concolor), onça-pintada (Panthera onca), entre outras (Leonel 2001).

Toda a área das comunidades está inserida na Zona Tampão da Área de Proteção Ambiental da Serra do Mar (Melo \& Salaroli 1990, Stucchi 1998) e faz parte do importante continuum ecológico formado pelas Unidades de Conservação da Serra de Paranapiacaba (Figura 1). Estão localizadas nas divisas leste do PETAR e sudeste

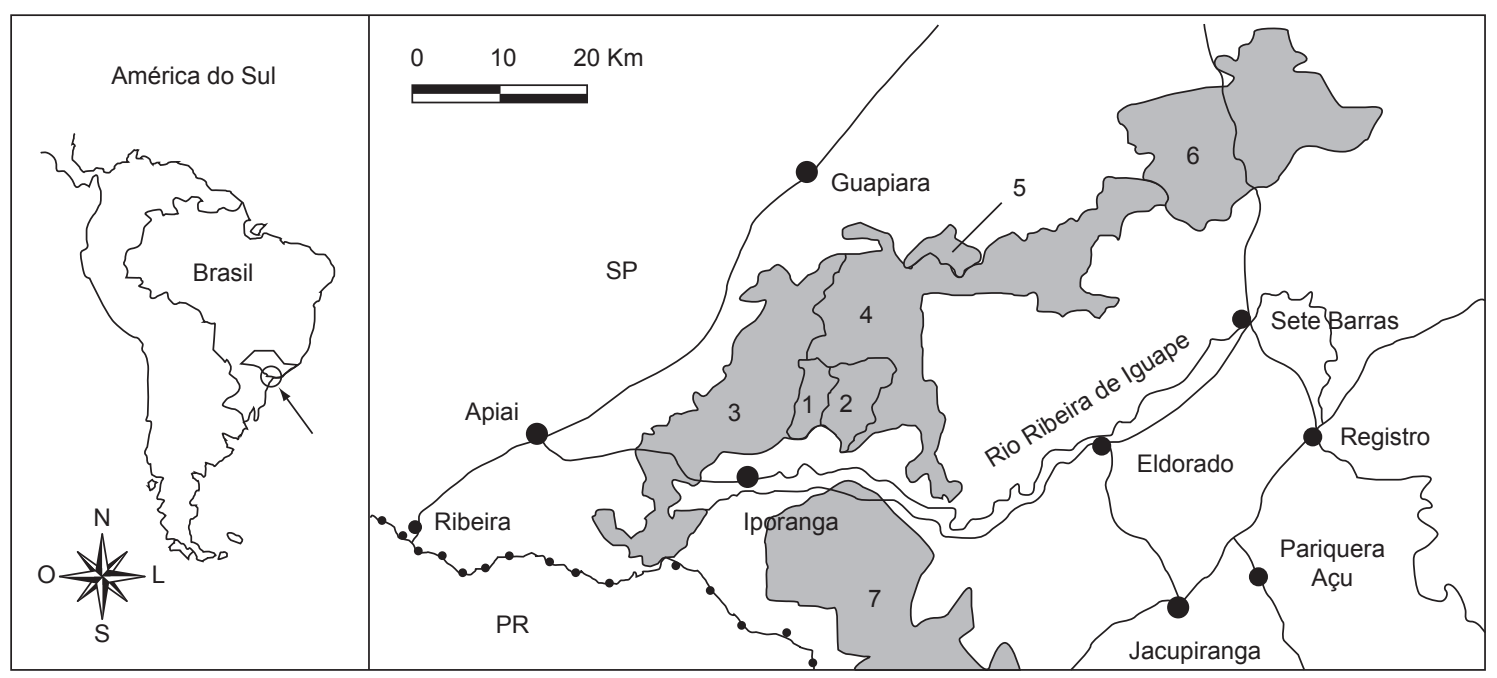

Figura 1. Comunidades 1) Maria Rosa e 2) Porto dos Pilões, localizadas no entorno das unidades de conservação; 3) PETAR; 4) Intervales; 5) Xitué; 6) Carlos Botelho; e 7) Jacupiranga, no Sudeste do Estado de São Paulo.

Figure 1. Maria Rosa 1) and Porto dos Pilões 2) communities, located in the surroundings of the conservation units; 3) PETAR; 4) Intervales; 5) Xitué; 6) Carlos Botelho; and 7) Jacupiranga, in Southeastern Sao Paulo State. 
do Parque Estadual Intervales, entre os rios Pilões e Itacolomi. As áreas de ambas as comunidades se encontram bastante preservadas com apenas cerca de $10 \%$ de áreas de pastagens e plantações. São as comunidades quilombolas do Vale do Ribeira mais isoladas e com grande dificuldade de acesso apesar de bastante próximas entre si - aproximadamente $6 \mathrm{~km}$ de estrada de terra - o que propicia uma grande interação entre seus habitantes (Fundação Florestal 1997). Para acessá-las a partir da cidade de Iporanga, é necessário percorrer $18 \mathrm{~km}$ de estrada asfaltada (SP-165) até a balsa do Poço Grande ( $\mathrm{km} 22$ ) no rio Ribeira de Iguape, mais 15 e $10 \mathrm{~km}$ de estrada de terra até as comunidades Maria Rosa e Porto dos Pilões, respectivamente (Melo \& Salaroli 1990).

\subsection{Descrição das comunidades quilombolas Maria Rosa e Porto dos Pilões}

As comunidades Maria Rosa e Porto dos Pilões são remanescentes de quilombos que têm sua origem nos séculos XVIII e XIX. O território que ocupam identifica-se com sua história de busca pela liberdade e pela autonomia. Esses quilombolas ocuparam territórios de difícil acesso, em geral vales e serras próximos a mananciais e a grandes rios (Diário Oficial do Estado de São Paulo 1998).

Inicialmente, a entrada da população negra escrava na região do Vale do Ribeira se deu com a mineração do ouro no século XVII. Com o declínio da mineração na região e a descoberta do ouro em maior quantidade em Minas Gerais, os proprietários de lavras seguiram para lá, levando consigo poucos escravos e deixando a maioria deles na região. Provavelmente, esses escravos remanescentes miscigenaramse com índios da região e deram origem às populações hoje residentes em Pilões, Maria Rosa e outros quilombos do Vale do Ribeira (Diário Oficial do Estado de São Paulo 1998).

Atualmente, 32 famílias residem nas duas comunidades. A emigração foi intensa no passado e continua até hoje. Os moradores que permaneceram não possuem alternativas econômicas eficazes e sofrem com a intensa fiscalização em torno da extração dos recursos naturais e da abertura de lavouras. Quase todas as famílias sobrevivem da agricultura de subsistência, sendo as culturas mais comuns o arroz, o feijão, o milho e a mandioca. A criação de animais domésticos também é de pequena escala e voltada para a subsistência. As criações mais comuns são de aves (muitos galináceos e poucos gansos e patos), suínos, eqüinos e as menos comuns são de bovinos, caprinos, entre outros. Também sobrevivem da atividade extrativista de cipós, madeiras, ervas medicinais e outros produtos florestais para construir casas, monjolos, engenho e canoas, e curar doenças. A maioria dos moradores obtém alguma renda ou a complementa por meio da exploração ilegal do palmito-juçara (Euterpe edulis), que cada vez mais se torna uma opção por ser um produto muito valorizado e de grande procura no mercado.

Em cada comunidade existe uma Associação de Moradores que surgiu devido à necessidade de um instrumento formal de organização e reivindicação social dos direitos da população (Melo \& Salaroli 1990). Até pouco tempo, as comunidades Maria Rosa e Pilões sofreram uma série de problemas em relação ao reconhecimento, à regularização e à titulação de suas terras. A sobreposição de suas terras com áreas que integravam o perímetro do Parque Estadual Intervales gerou um conflito desde a data de criação do Parque em 1995, já que o direito à terra era anteriormente previsto no Artigo 68 do Ato das Disposições Constitucionais Transitórias da Constituição Federal de 1988. Os quilombolas consideravam a sobreposição de seu território à área do Parque um entrave para a demarcação de suas terras. Somente a partir do Decreto Estadual $n^{\circ} .44 .293$, de 04 de outubro de 1999, ficou estabelecido que as comunidades Maria Rosa e Porto dos Pilões, bem como os outros remanescentes quilombolas, não integrariam mais o perímetro do Parque Estadual Intervales (http://www.socioambiental.org/nsa/detalhe?id=1249). Finalmente, no dia 15 de janeiro de 2001, o governador do Estado de São Paulo entregou às lideranças das comunidades de Maria Rosa e Pilões, o título de domínio de suas terras. A titulação é um grande avanço na luta pela efetivação dos direitos territoriais, pois a sobrevivência física e cultural dos quilombolas depende da garantia do território onde possam morar, plantar e exercer suas atividades tradicionais (http://www.socioambiental.org/nsa/detalhe?id=1324).

\section{Entrevistas}

Como as observações diretas da predação de criações por onças são em geral escassas, a aplicação de questionários foi a melhor maneira de avaliar a ocorrência de predações, bem como levantar a opinião da população das comunidades Maria Rosa e Porto dos Pilões em relação ao problema. As entrevistas vêm sendo freqüentemente utilizadas para avaliar as perdas causadas por predadores e fornecer informações sobre a percepção da população em relação ao conflito (por ex., ver Robel et al. 1981, Schaefer et al. 1981, Oli et al. 1994, Manzatti 1999, Mazzolli et al. 2002, Conforti \& Azevedo 2003, Palmeira 2004, Zimmermann et al. 2005, Michalski et al. 2006).

Inicialmente, as comunidades foram visitadas mensalmente no período de 05/2000 a 01/2001, exceto em julho e setembro. Com o auxílio do Presidente da Associação de Moradores do Bairro Maria Rosa foi possível conhecer boa parte dos moradores para divulgar o início da pesquisa. Todas as propriedades foram selecionadas, com exceção de quatro onde os proprietários se encontravam ausentes durante todo o período da pesquisa.

Para quantificar a predação por onças e levantar a opinião local em relação ao conflito foram realizadas entrevistas semi-estruturadas em 28 propriedades, representando $87 \%$ do total de propriedades existentes nas duas comunidades (Figura 2). As entrevistas foram realizadas apenas com o responsável de cada propriedade selecionada. Cada entrevista teve a duração média de 1 hora e foi realizada uma vez com cada proprietário. Para obter maior consistência na coleta das informações, as entrevistas foram iniciadas seis meses após a primeira visita às comunidades, conforme proposto por Oli et al. (1994). Durante esse período, foi possível conviver com os moradores, acompanhar suas atividades cotidianas e visitar as propriedades uma vez a cada mês para monitorar se havia ocorrido alguma predação recente ou algum avistamento de onça.

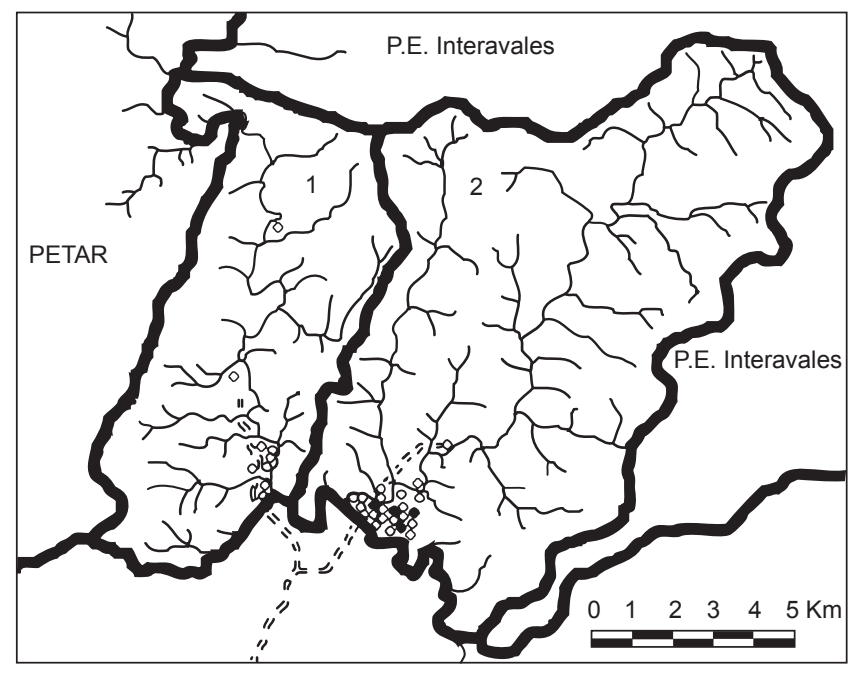

Figura 2. Propriedades pesquisadas (0) e propriedades não-pesquisadas $(\bullet)$ nas comunidades Maria Rosa (1) e Porto dos Pilões (2).

Figure 2. Researched properties (o) and non-researched properties $(\bullet)$ in the Maria Rosa (1) and Porto dos Pilões (2) communities. 
O questionário foi dividido em três partes: 1) Perfil dos entrevistados, 2) Predação por onças e 3) Percepção local (Tabela 1). Nas partes 1 e 2, os proprietários foram entrevistados formalmente por meio de perguntas diretas. Na parte 3, foram realizadas perguntas informais e não estruturadas, procurando não influenciar a opinião dos entrevistados. Os entrevistados sempre expressavam suas opiniões em relação ao conflito com respostas espontâneas sem a necessidade de utilizar as questões de múltipla escolha que apenas foram colocadas no protocolo para facilitar a sistematização do mesmo já durante o período de coleta de dados.

Para traçar o perfil dos entrevistados, foram apurados a idade, o local de origem, o período de moradia na região, o número de habitantes da residência, o número de pessoas economicamente ativas, a atividade econômica principal e a renda mensal. Para avaliar os danos causados por onças, foram investigados o número e o tipo de criações mantidas na propriedade, as práticas de manejo, o número e o tipo de criações atacadas por onças, o avistamento ou não da criação abatida, entre outras observações. Em adição, foram anotados os relatos mais comuns ou marcantes a respeito das onças e as sugestões levantadas pelos habitantes para reduzir os ataques. Para evitar que os dados fossem desviados com relação às lembranças dos entrevistados em um passado mais distante, apenas foram considerados os ataques mais recentes (de 1998 a 2000), excluindo os relatos de anos anteriores. Todos os eventos de predação ocorridos nas propriedades foram confirmados por outros entrevistados, como forma de triangulação dos dados. Em todas as entrevistas, os proprietários sempre indicavam o nome de outros proprietários que também tiveram perdas. Como as duas comunidades apresentaram características gerais semelhantes, todos os dados coletados foram agrupados nas análises.

\section{Análise de dados}

O peso médio (kg) e o valor econômico de cada tipo de criação foram levantados com os próprios entrevistados e consultados nos mercados da cidade de Iporanga. Posteriormente, foram calculados valores médios dos pesos $(\mathrm{kg})$ e dos preços estipulados para cada tipo de criação.

Para estimar a biomassa do estoque $\left(\mathrm{kg} / \mathrm{km}^{2}\right)$ e a biomassa predada $\left(\mathrm{kg} / \mathrm{km}^{2}\right)$, o peso médio $(\mathrm{kg})$ de cada tipo de criação foi multiplicado pelo número total de indivíduos e dividido pela área $\left(\mathrm{km}^{2}\right)$

Tabela 1. Questionário semi-estruturado utilizado durante as entrevistas nas comunidades quilombolas de Maria Rosa e Porto dos Pilões.

Table 1. Semi-structured questionnaire used during the interviews in the quilombola communities of Maria Rosa and Porto dos Pilões.

\begin{tabular}{lll}
\hline & Perfil do entrevistado & Data:_/_ \\
Local: & & N: \\
Nome: & Tempo na região: & Idade: \\
Local de origem: & Número de trabalhadores: \\
Número de moradores na residência: & Renda mensal: \\
Atividade principal: & Predação por onças \\
\hline
\end{tabular}

1. Quais e quantas criações domésticas possue?
( ) bovinos
( ) eqüinos
( ) suínos
( ) galináceos
( ) cachorros
( ) caprinos

( ) outras/Quais?

2. Que tratamento é dado para cada tipo de criação? Como é a alimentação e o local da pernoite?

3. Como cada criação é utilizada (p/que fim)?

4. Já teve alguma criação atacada por onças?

5. Quais e quantas criações foram atacadas por onças?

6. Local? Data? Horário (dia ou noite)?

7. Visualizou a onça?

( ) $\mathrm{S}$

( ) onça-parda

( ) $\mathrm{S}$

9. Viu a carcaça da criação?

( ) coberta

\section{( ) $\mathrm{N}$}

( ) onça-pintada

( ) $\mathrm{N}$

() descoberta

11. Que partes da carcaça estavam consumidas?

12. Que fez depois do acontecido?

\section{Percepção}

13. O que você acha mais adequado para resolver o problema da predação?
( ) manejo das criações
( ) indenização financeira
( ) remover as onças "problemas" do local
( ) exterminação total das onças
( ) não sabe
( ) sugestões. Quais?

14. Quem deve arcar com os prejuízos causados por onças?

( ) governo

( ) proprietários das criações

( ) não sabe

( ) sugestões. Quais?

15. Acha necessário controlar os ataques?
( ) $\mathrm{S}$
( ) $\mathrm{N}$
( ) $\mathrm{S}$
( ) $\mathrm{N}$

16. Aceitaria sugestões para evitar os ataques?

17. Observações: 
das comunidades, como utilizado por Schaller (1983), Crawshaw \& Quigley (1984) e Polisar et al. (2003). Na pesquisa de Schaller (1983), foram considerados os pesos $(\mathrm{kg})$ de indivíduos adultos e os ajustes por classe etária foram realizados somente quando possível. Nesta pesquisa, foram considerados apenas os pesos médios de indivíduos adultos, já que não foi possível classificar a faixa etária de todas as criações domésticas.

Para calcular o prejuízo econômico causado pela predação, o número de ataques foi multiplicado pelo valor de cada tipo criação. Os valores em reais ( $\mathrm{R} \$$ ) foram convertidos em unidade de dólares americanos (US\$) em 31/01/2001 (US\$ $1=\mathrm{R} \$ 1,97$ ), data final das coletas de campo. Os cachorros foram excluídos da estimativa das perdas econômicas por não serem comercializados.

Para avaliar a existência de relação entre o número de predações e o número de animais domésticos nas propriedades, foi utilizado o teste não-paramétrico de correlação de Spearman $\left(\mathrm{r}_{\mathrm{s}}\right)$, dada a nãonormalidade dos dados. O teste foi realizado considerando todos os tipos de criação conjuntamente e separadamente para cada tipo de criação. Para verificar se as opiniões sobre o conflito dependeram de fatores como a idade, o local de origem, o tempo na região, a atividade e a renda mensal dos proprietários, assim como do tamanho do rebanho e do número de predações foi utilizado o teste Qui-quadrado de acordo com Zar (1996).

\section{Resultados}

\section{Perfil dos entrevistados}

Do total de entrevistados, $89 \%(\mathrm{n}=25)$ eram homens e $11 \%$ $(\mathrm{n}=3)$ mulheres. A idade média foi 51 anos $(\mathrm{SD}=16)$, com mínima de 23 e máximo de 72 anos, sendo $89 \%(\mathrm{n}=25)$ natural das próprias comunidades e $11 \%(n=3)$ de outras regiões. O tempo médio de moradia na região foi 45 anos $(\mathrm{SD}=20)$, com mínimo de 3 e máximo de 72 anos. Cada família é composta por cerca de quatro pessoas e possui cerca de duas que trabalham, sendo bastante comum a organização familiar para trabalhar na lavoura de subsistência. As atividades principais são lavradores $(61 \% ; n=17)$, aposentados $(21 \% ; n=6)$ e outras atividades $(18 \% ; n=5)$. A renda mensal é baixa, sendo que $36 \%(\mathrm{n}=10)$ recebem um salário mínimo por mês (75 US\$), $32 \%$ $(\mathrm{n}=9)$ não têm renda econômica, $18 \%(\mathrm{n}=5)$ recebem acima de dois salários mínimos (de 150 a 275 US\$) e 14\% $(n=4)$ recebem abaixo de um salário mínimo (de 25 a 40 US\$).

Tabela 2. Número de animais domésticos por propriedade nas comunidades Maria Rosa (MR) e Porto dos Pilões (PP) para o ano de 2000.

Table 2. Number of domestic animals per household in the Maria Rosa (MR) and Porto dos Pilões (PP) communities in the year 2000.

\begin{tabular}{|c|c|c|c|c|c|c|c|c|}
\hline Comunidade & Propriedade & Aves & Suínos & Bovinos & Eqüinos & Caprinos & Cachorros & Total \\
\hline $\mathrm{MR}$ & 1 & 50 & 13 & - & 10 & 2 & 8 & 83 \\
\hline MR & 2 & 50 & 8 & - & 1 & - & 1 & 60 \\
\hline MR & 3 & 25 & 6 & - & 3 & - & 3 & 37 \\
\hline MR & 4 & 10 & 5 & - & 3 & - & 3 & 21 \\
\hline MR & 5 & 40 & 5 & - & 2 & - & 3 & 50 \\
\hline MR & 6 & 50 & 30 & 21 & 6 & - & 8 & 120 \\
\hline MR & 7 & 25 & 7 & - & 3 & - & 1 & 36 \\
\hline MR & 8 & 15 & 3 & 20 & 4 & - & 2 & 44 \\
\hline MR & 9 & 6 & - & - & 2 & - & 3 & 11 \\
\hline $\mathrm{PP}$ & 10 & 40 & - & - & 2 & - & 1 & 43 \\
\hline $\mathrm{PP}$ & 11 & 30 & - & - & 4 & - & 1 & 35 \\
\hline PP & 12 & 25 & - & - & 2 & - & - & 27 \\
\hline PP & 13 & 40 & 11 & 45 & 14 & - & 3 & 113 \\
\hline PP & 14 & 15 & - & - & 3 & - & - & 18 \\
\hline PP & 15 & 20 & - & - & - & - & - & 20 \\
\hline PP & 16 & - & - & - & 3 & - & - & 3 \\
\hline $\mathrm{PP}$ & 17 & 30 & 2 & - & 2 & - & 1 & 35 \\
\hline PP & 18 & - & - & - & 1 & - & - & 1 \\
\hline $\mathrm{PP}$ & 19 & 12 & - & - & - & - & - & 12 \\
\hline PP & 20 & - & 2 & - & - & - & - & 2 \\
\hline PP & 21 & 6 & - & - & - & - & - & 6 \\
\hline PP & 22 & - & - & - & - & - & - & - \\
\hline $\mathrm{PP}$ & 23 & 10 & - & - & - & - & 2 & 12 \\
\hline PP & 24 & 35 & - & - & 1 & - & 2 & 38 \\
\hline $\mathrm{PP}$ & 25 & - & - & - & - & - & - & - \\
\hline PP & 26 & 10 & - & - & - & - & - & 10 \\
\hline PP & 27 & - & - & - & 2 & - & 1 & 3 \\
\hline PP & 28 & - & - & - & - & - & - & - \\
\hline Total & 28 & 549 & 92 & 86 & 68 & 2 & 43 & 840 \\
\hline Biomassa (kg) & - & 1.098 & 5.520 & 25.800 & 20.400 & 100 & 654 & 53.563 \\
\hline
\end{tabular}




\section{Predação por onças}

A distribuição do tipo e número de criações por propriedade não foi uniforme (Tabela 2). Apesar de muitas propriedades manterem aves $(n=25)$, eqüinos $(n=19)$ e cachorros $(n=16)$, poucas têm suínos $(\mathrm{n}=11)$, bovinos $(\mathrm{n}=3)$ e caprinos $(\mathrm{n}=1)$. Apenas três propriedades (11\%) não mantinham criações domésticas durante o período da pesquisa. As criações mais numerosas foram as aves (549 animais nas comunidades), seguidas pelos suínos (92 animais), bovinos (86 animais), eqüinos (68 animais), cachorros (43 animais) e caprinos (2 animais). Contudo, a maior biomassa total nas comunidades foi a de bovinos $(25.800 \mathrm{~kg})$, seguido pelos eqüinos $(20.400 \mathrm{~kg})$, suínos $(5.520 \mathrm{~kg})$, aves $(1.098 \mathrm{~kg})$, cachorros $(654 \mathrm{~kg})$ e caprinos $(100 \mathrm{~kg})$.

Foram identificados quatro tipos de manejo: o extensivo, o semiextensivo, o confinamento noturno e o confinamento sazonal. No manejo extensivo, as criações ficam soltas por período integral para reduzir os custos de manutenção. No semi-extensivo, as criações ficam em uma área cercada e dependem dos alimentos cultivados nas propriedades. No confinamento noturno, as criações ficam soltas de dia e presas à noite, para evitar os ataques de predadores silvestres. No confinamento sazonal, as criações ficam presas somente em determinadas épocas do ano para não causarem danos às lavouras. No geral, o manejo mais utilizado foi o extensivo para todos os tipos de criações (379 animais), seguido pelo confinamento noturno para as aves e os eqüinos (365 animais), confinamento sazonal para os suínos e os eqüinos (73 animais) e semi-extensivo para os bovinos e os eqüinos (23 animais) (Tabela 3). Os proprietários utilizaram mais de um tipo de manejo simultaneamente conforme o tipo de criação, época do ano, distâncias entre as propriedades e as lavouras, necessidade econômica, entre outros fatores. Por isso, não foi possível avaliar se as predações foram influenciadas pelo tipo de manejo adotado em cada propriedade.

Em relação às predações, $75 \%(n=21)$ dos entrevistados já perderam algum tipo de criação devido aos ataques por onças. Entre 1998 a 2000, metade destes $(n=14)$ teve criações atacadas por onças. A predação apresentou uma associação razoável $\left(\mathrm{p}<0,05, \mathrm{r}_{\mathrm{s}}=0,41\right)$ com o número total de animais domésticos mantidos nas propriedades, ou seja, a predação foi mais freqüente nas propriedades que tinham um maior número de animais domésticos. Quando cada tipo de criação foi considerado separadamente, apenas para os eqüinos o número de animais predados apresentou uma associação razoável com o número de animais mantidos nas propriedades (eqüinos $\mathrm{p}<0,05, \mathrm{r}_{\mathrm{s}}=0,43$; suínos $-\mathrm{p}>0,05, \mathrm{r}_{\mathrm{s}}=0,17$; caprinos $-\mathrm{p}>0,05, \mathrm{r}_{\mathrm{s}}=-0,03$; cachorros $-\mathrm{p}>0,05, \mathrm{r}_{\mathrm{s}}=0,18$ ).

Os suínos foram os mais predados (29 animais), seguidos pelos eqüinos (19 animais), caprinos (18 animais) e cães (3 animais), totalizando 69 animais domésticos atacados por onças (Tabela 4). Apesar das aves serem os animais mais comumente criados nas propriedades, os relatos de predação a estes animais foram atribuídos somente aos gatos-do-mato (Leopardus spp.), gambás (Didelphis sp.) e morcegosvampiros (Diphylla sp.). Além disso, os bovinos que representaram a maior biomassa disponível nas comunidades também não foram predados por onças. Por outro lado, os animais mais predados (suínos, seguidos de eqüinos), não representam as criações mais comuns na região, nem em termos do número total de animais nem em termos da biomassa total, o que indica que a predação por onças na região seja seletiva e que suínos e eqüinos sejam mais vulneráveis.

Segundo alguns entrevistados $(n=9)$, muitos ataques ocorreram durante determinadas épocas do ano, especialmente a partir de agosto, período que corresponde ao final do inverno. Após sucessivos ataques, a Fundação Florestal e os quilombolas solicitaram a presença do Centro Nacional de Pesquisa para a Conservação de Predadores Naturais do Instituto Brasileiro do Meio Ambiente e dos Recursos Naturais Renováveis (CENAP/IBAMA), que enviou uma especialista para confirmar as denúncias de três ataques atribuídos às onças na comunidade Maria Rosa em 18/10/1999. Segundo Cavalcanti (1999), os três eqüinos vistoriados apresentaram características típicas do ataque de onça-pintada como fraturas na região superior do crânio, marcas de unhas e perfurações dos caninos, cortes profundos e escoriações na região do pescoço e nos traseiros.

Em 2000, a predação reduziu consideravelmente em relação aos anos anteriores (1998 e 1999). Foram freqüentes os relatos de que a matança de onças era uma prática comum no passado e que atualmente foi reduzida por causa da intensa fiscalização. Apesar disso, alguns entrevistados $(n=7)$ confirmaram que uma onça-pintada foi caçada em 1999 quando o índice de predações atingiu seu máximo, o que poderia justificar a redução das predações no ano de 2000.

Oitenta e um por cento das predações (56) foram confirmadas pelos proprietários por meio da visualização dos animais abatidos que, em geral, apresentavam fraturas típicas do ataque por onças, especialmente na cabeça e no abdômen. Os desaparecimentos $(13 \% ; 9)$ das criações foram atribuídos aos ataques de onças quando,

Tabela 4. Número de animais domésticos atacados por onças de 1998 a 2000 nas comunidades Maria Rosa e Porto dos Pilões.

Table 4. Number of domestic animals attacked by large cats from 1998 to 2000 in the Maria Rosa and Porto dos Pilões communities.

\begin{tabular}{lccccc}
\hline $\begin{array}{c}\text { Criações } \\
\text { domésticas }\end{array}$ & $\mathbf{1 9 9 8}$ & $\mathbf{1 9 9 9}$ & $\mathbf{2 0 0 0}$ & Total & \% \\
\hline Suínos & 17 & 12 & - & 29 & 42 \\
Eqüinos & 9 & 9 & 1 & 19 & 28 \\
Caprinos & - & 18 & - & 18 & 26 \\
Cachorros & 1 & 2 & - & 3 & 4 \\
Total & 27 & 41 & 1 & 69 & 100,0 \\
\hline
\end{tabular}

Tabela 3. Número de animais domésticos em relação ao tipo de manejo nas comunidades Maria Rosa e Porto dos Pilões.

Table 3. Number of domestic animals in relation to the kind of management in the Maria Rosa and Porto dos Pilões communities.

\begin{tabular}{lcccc}
\hline Criações domésticas & Extensivo & Confinamento sazonal & Confinamento noturno & Semi-extensivo \\
\hline Aves & 195 & - & 354 & - \\
Suínos & 24 & 68 & - & - \\
Eqüinos & 49 & 5 & -11 & 3 \\
Bovinos & 66 & - & - & 20 \\
Caprinos & 2 & - & - & - \\
Cachorros & 43 & 73 & 365 & 23 \\
Total & 379 & - & - \\
\hline
\end{tabular}


simultaneamente, ocorriam predações nas propriedades vizinhas com a visualização do animal abatido associadas a rastros e a marcações de onças, confirmando a ocorrência do predador na propriedade. $\mathrm{O}$ restante $(6 \% ; 4)$ foi encontrado ainda vivo e com arranhões nas partes traseiras e ferimentos no pescoço. Cerca de $15 \%$ (10) dos ataques foram atribuídos às onças cuja espécie não foi citada, $84 \%$ (58) foram atribuídos às onças-pintadas e apenas $1 \%$ (1) às onças-pardas. Contudo, os entrevistados não sabiam reconhecer as diferenças entre os animais predados por onça-pintada e por onça-parda.

A predação média anual foi de 23 animais $(S D=20)$, equivalente a $3 \%$ do estoque total de criações. Os eqüinos representaram a maior biomassa consumida por onças seguidos pelos suínos, caprinos e cachorros (Tabela 5). A biomassa predada foi estimada em $29 \mathrm{~kg} / \mathrm{km}^{2}$ por ano, equivalente a $5 \%$ da biomassa do estoque total. O prejuízo econômico resultante da predação por onças foi o total de US\$ 4.672, com médias de US\$ 1.557 por ano e US\$ 130 por mês. O prejuízo econômico anual representou 5\% do valor do estoque total (US\$ 30.714). O prejuízo por propriedade foi cerca de US\$ 56 por ano ou US\$ 5 por mês, equivalente a cerca de $7 \%$ da renda mensal média dos proprietários.

\section{Percepção local}

Para resolver o problema, 54\% $(\mathrm{n}=15)$ disseram que seria necessário exterminar as onças do local, $14 \%(\mathrm{n}=4)$ optaram em remover a onça "problema" da região, $11 \%(\mathrm{n}=3)$ acreditam que a indenização monetária seria a melhor solução e $21 \%(n=6)$ não souberam responder.

As opiniões para reduzir os ataques não dependeram das classes de idade dos entrevistados $\left(\mathrm{x}^{2}=3,47, \mathrm{gl}=3, \mathrm{p}>0,05\right)$, do local de origem $\left(x^{2}=3,43, g l=3, p>0,05\right)$, da atividade principal $\left(x^{2}=0,67\right.$, $\mathrm{gl}=3, \mathrm{p}>0,05)$ e da renda econômica dos entrevistados $\left(\mathrm{x}^{2}=0,79\right.$, $\mathrm{gl}=3, \mathrm{p}>0,05)$. As opiniões também não dependeram do tamanho das criações mantidas pelos entrevistados $\left(\mathrm{x}^{2}=4,48, \mathrm{gl}=3, \mathrm{p}>0,05\right)$ e da ocorrência de predação nas propriedades dos entrevistados $\left(\mathrm{x}^{2}=3,11, \mathrm{gl}=3, \mathrm{p}>0,05\right)$.

Para reduzir os constantes ataques por onças, um proprietário trocou seu rebanho de caprinos por bovinos. Em todas as propriedades, os cachorros são mantidos sempre soltos para alertar a presença de possíveis predadores. Segundo os entrevistados, quando há alguma onça nas redondezas das propriedades, as criações se aproximam da casa e os cachorros apresentam seu comportamento alterado.

Todos os entrevistados $(100 \%, \mathrm{n}=28)$ acreditam ser necessário haver algum controle da predação por onças e aceitariam sugestões de terceiros para reduzir os ataques. Pouco mais da metade $(53 \% ; \mathrm{n}=15)$ atribuíram ao governo a responsabilidade de arcar com os prejuízos causados pela predação, enquanto apenas $4 \%(n=1)$ disseram que a responsabilidade deveria ser do proprietário das criações e $43 \%$ ( $\mathrm{n}=12)$ não souberam responder.

Todos os entrevistados $(\mathrm{n}=28)$ relataram temer serem atacados por onças. Tal sentimento se alastrou entre os habitantes, especialmente depois que um morador foi atacado por uma onça-pintada na comunidade Maria Rosa. Em 05/1998, por volta das 10:00 horas, uma onça-pintada matou cinco porcos e feriu os demais dentro do chiqueiro de uma propriedade. Quando foi surpreendida pela presença do proprietário, a onça o atacou, arranhando suas costas e cabeça. A onça fugiu e, em seguida, o morador foi encaminhado muito ferido para o Hospital Regional do Vale do Ribeira, em Pariquera-Açú. Após o ataque, a vítima ficou cada vez mais debilitada, foi enfraquecendo e faleceu cerca de 10 meses após o ataque (03/1999). O Hospital não autorizou informar a causa oficial da morte a outrem que não familiar do paciente ou médico assistente. Contudo, os entrevistados relataram que acreditam que a vítima morreu após diversas infecções causadas pelo "veneno" das unhas da onça na ocasião do ataque.

Por meio da coleta participativa foi possível registrar seis ocorrências de onças nas áreas das comunidades entre 03/2000 e 01/2001. Cinco ocorrências de onças cuja identificação da espécie não foi possível e uma ocorrência de onça-parda. Em 05/2000, por volta das 17 horas, o técnico da Fundação Florestal e o Presidente da Associação de Moradores do Bairro Maria Rosa (Wagner Gomes Portilho \& Antonio Trabuco, com. pess.), visualizaram uma onça-parda atravessando a estrada de acesso às comunidades Maria Rosa e Pilões. Em 08/2000, um entrevistado encontrou duas carcaças de veado (Mazama spp.) associadas aos rastros de uma onça próximas a divisa com o PETAR. Em quatro ocasiões (05/2000, 07/2000 e dois eventos em 01/2001) alguns moradores da comunidade Maria Rosa visualizaram os rastros de onças nas redondezas de suas propriedades.

\section{Discussão}

Os ataques causados por onças foram relativamente raros, mas causaram prejuízos financeiros elevados, considerando o pequeno número de criações e a baixa renda econômica dos proprietários. A predação é considerada mais importante economicamente para os pequenos produtores que podem vir a perder seu único animal. Segundo Oli et al. (1994) e Nowell \& Jackson (1996), por exemplo, quando as criações são mantidas para subsistência e têm uma baixa produtividade, os prejuízos causados por predadores são maiores para estes criadores do que para produtores de grande escala.

De acordo com Jackson \& Nowell (1996), a predação por felinos é baixa e, geralmente, representa até $3 \%$ do estoque anual. Da mesma forma, a predação média anual $(23, \mathrm{SD}=20)$ observada neste estudo representou $3 \%$ do estoque total de criações, percentagem semelhante àquela registrada em várias localidades e contextos. Por exemplo, no

Tabela 5. Biomassa do estoque total de 2000 e biomassa a média anual predada de 1998 a $2000\left(\mathrm{~kg}\right.$ e $\left.\mathrm{kg} / \mathrm{km}^{2}\right)$ nas comunidades Maria Rosa e Porto dos Pilões.

Table 5. Total stock biomass from 2000 and average annual predated biomass from 1998 to $2000\left(\mathrm{~kg}\right.$ and $\left.\mathrm{kg} / \mathrm{km}^{2}\right)$ in Maria Rosa and Porto dos Pilões communities.

\begin{tabular}{lcccc}
\hline Criações domésticas & Biomassa total $(\mathbf{k g})$ & Biomassa Predada $(\mathbf{k g})$ & Biomassa total $\left(\mathbf{k g} / \mathbf{k m}^{2}\right)$ & ${\text { Biomassa Predada }(\mathbf{k g} / \mathbf{k m})^{2}}$ \\
\hline Aves & 1.098 & - & 11 & - \\
Suínos & 5.520 & 580 & 57 & 6 \\
Bovinos & 25.800 & - & 269 & - \\
Eqüinos & 20.400 & 1.900 & 212 & 20 \\
Caprinos & 100 & 300 & 1 & 3 \\
Cachorros & 645 & 15 & 7 & 0 \\
Total & 53.563 & 2.795 & 558 & 29 \\
\hline
\end{tabular}


entorno da Área de Conservação de Annapurna no Nepal habitada por comunidades tradicionais, a predação causada por leopardos-dasneves representou 2,6\% do estoque total de criações (Oli et al. 1994). No Parque Nacional de Tsavo no Quênia, a maioria das predações foi causada por leões e representou 2,4\% do estoque anual (Patterson et al. 2004). Em fazendas no Pantanal Mato-grossense a predação por onças-pintadas representou 2,3\% do estoque total (Zimmermann et al. 2005). No sul da Amazônia, a perdas não excederam 1,2\% do estoque total (Michalski et al. 2006). Esta taxa de predação foi, no entanto, superior àquela observada em propriedades no entorno do Parque Nacional do Iguaçu (Conforti \& Azevedo 2003) e em uma propriedade em Goiás (Palmeira 2004) onde a predação por onças representou $0,4 \%$ do estoque anual. Da mesma forma, ela é superior àquela observada em províncias de Qinghai e Gansu na China, nas quais a predação por leopardos-das-neves representou $0,5 \%$ do estoque anual (Schaller et al. 1988).

A biomassa média anual do estoque total de criações $\left(558 \mathrm{~kg} / \mathrm{km}^{2}\right)$ foi muito menor do que a biomassa observada em outros estudos de predação por onças. Foram registrados $15.528 \mathrm{~kg} / \mathrm{km}^{2}$ em uma propriedade rural de Goiás (Palmeira, 2004), $7.363 \mathrm{~kg} / \mathrm{km}^{2}$ no Llanos Venezuelanos (Polisar et al. 2003), 4.900 kg/km² na Fazenda Estância Miranda (Crawshaw \& Quigley 1984) e de $3.750 \mathrm{~kg} / \mathrm{km}^{2}$ no Acurizal (Schalller 1983), ambas no Pantanal.

O prejuízo econômico resultante da predação representou $5 \%$ do valor do estoque anual de criações e foi muito maior do que o prejuízo de $0,3 \%$ estimado em Goiás por Palmeira (2004). O prejuízo médio anual de US\$ 4.672 das comunidades quilombolas foi proporcionalmente maior que os US\$ 1.890 estimados para algumas propriedades em Santa Catarina (Mazzolli et al. 2002), ou então os US\$ 4.250 (Manzatti 1999) e US\$ 3.000, observados no entorno do Parque Nacional de Iguaçu (Conforti \& Azevedo 2003). Em contraste, foi bem menor que US\$ 8.749 de prejuízos causados por leões no Quênia (Patterson et al. 2004).

Os tipos de criações mais atacadas - suínos e eqüinos - e a maior incidência de ataques no final do inverno (outubro) indica que a predação de criações domésticas é aparentemente seletiva e possivelmente sazonal nas comunidades quilombolas estudadas. A presença de onças nas áreas das comunidades também foi aparentemente sazonal e não teve associação com a ocorrência de predações, já que durante o período de investigação os proprietários constataram a presença de onças nas proximidades de suas propriedades, mas não relataram nenhuma predação.

Os proprietários desenvolveram técnicas próprias para manejar seus rebanhos. Essas técnicas diferiram dependendo das necessidades da propriedade, ameaças por predadores silvestres e danos nas lavouras por criações domésticas. O fato de um proprietário trocar seu rebanho de caprinos por bovinos devido aos prejuízos resultantes da predação, ou então de vários proprietários utilizarem o confinamento noturno e o confinamento sazonal, demonstrou que o tipo de manejo foi utilizado e alterado quando ocorrem perdas ou quando existe alguma ameaça de grande prejuízo para a propriedade. Um fato semelhante foi observado no entorno do Parque Nacional do Iguaçú, onde vários proprietários haviam parado de criar ovelhas em decorrência dos ataques de onças (Manzatti 1999). Segundo o autor (op.cit.), os proprietários também não adotavam medidas específicas para prevenir a predação por mamíferos silvestres, sendo que, tais medidas só foram observadas nas áreas de maior incidência de danos.

Os entrevistados identificaram a maioria das predações por meio das carcaças. Em Foz do Iguaçú, Manzatti (1999), também observou que a carcaça do animal abatido foi a principal forma dos proprietários identificarem as predações. Os entrevistados atribuíram alguns desaparecimentos aos ataques de onças. Apesar da dificuldade de confirmar a causa real dos desaparecimentos, o fato é que a po- pulação atribuiu tais perdas ao ataque de onças, gerando conflitos. Os entrevistados não sabiam as diferenças entre a predação causada pelas duas espécies de onças, entretanto, atribuíram a maioria dos ataques $(84 \%)$ à onça-pintada. Tal fato sugere que esses dados foram desviados pela maior representatividade da onça-pintada no imaginário dos quilombolas, afinal era a espécie que eles mais conheciam. No entorno do Parque Nacional de Foz do Iguaçu, os proprietários também atribuíram a maior parte dos ataques às onças-pintadas, além disso, todos conheciam a onça-pintada enquanto que apenas $44 \%$ conheciam a onça-parda (Conforti \& Azevedo 2003).

A predação de criações domésticas por onças faz com que os quilombolas tenham uma visão bastante negativa frente à presença destes predadores na região, especialmente após o ataque fatal de uma onça-pintada a um morador da comunidade Maria Rosa. Embora os ataques de onças a humanos sejam raros (Beier 1991, Foerster 1996, Perovic \& Herrán 1998) a população quilombola expressou ter muito medo. Durante as entrevistas ficou claro que todos os habitantes $(100 \%, \mathrm{n}=28)$ acreditam na possibilidade de também serem atacados. No Pantanal, 34\% acreditam que a onça-pintada seja uma ameaça à vida dos seres humanos (Zimmermann et al. 2005); em Foz do Iguaçu, 52\% (Conforti \& Azevedo 2003). Esta situação de conflito se tornou um aspecto negativo para a conservação dos remanescentes populacionais de onças, que sofrem sérios riscos de serem eliminadas pela população residente.

A maior parte dos entrevistados $(54 \%, \mathrm{n}=15)$ acredita que o animal deva ser eliminado de alguma maneira. Já os proprietários do entorno do Parque Nacional de Foz do Iguaçu (PR) sugeriram a utilização de medidas preventivas para evitar os ataques às criações (39\%) e a translocação das onças depredadoras (35\%) (Conforti \& Azevedo 2003). No norte do Pantanal, a percepção positiva em relação às onças-pintadas não garante que os fazendeiros as preservem. Foi comum os entrevistados expressarem que a onça-pintada merece ser protegida, mas não em suas propriedades (Zimmermann et al. 2005).

As opiniões negativas dos quilombolas não dependeram do perfil dos entrevistados, do tamanho das criações mantidas pelos entrevistados e da ocorrência de predação nas propriedades. Resultados semelhantes foram observados por Zimmermann et al. (2005) que encontraram poucas relações entre as opiniões sobre as onças-pintadas e os outros fatores. Para Zimmermann et al. (2005) essas atitudes são moldadas especialmente pelas percepções individuais, crenças e valores, sendo influenciadas pela educação, formação familiar, tradição e cultura.

Cerca de metade dos entrevistados $(53 \% ; \mathrm{n}=15)$ atribuíram ao governo a responsabilidade de arcar com os prejuízos causados pela predação, porcentagem significativamente menor que aquela obtida no Pantanal (80\%) (Zimmermann et al. 2005). Muitos entrevistados também se mostraram relutantes em confinar suas criações porque a disponibilidade de alimentos é maior quando as criações são mantidas soltas, facilitando o manejo e diminuindo o custo econômico. Aliado a esse fato, eles acreditam que é impossível evitar o ataque das onças mesmo quando as criações são confinadas. Apesar disso, todos os entrevistados acreditaram ser necessário haver algum controle da predação por onças e aceitariam sugestões de terceiros para reduzirem os ataques, semelhante aos 94\% observado por Zimmermann et al. (2005). No entorno do Parque Nacional de Iguaçú, a maioria dos proprietários $(71 \%)$ mudaria suas práticas de manejo caso tivessem apoio institucional (Conforti \& Azevedo 2003). Estas observações demonstram a necessidade e a importância do envolvimento de instituições ambientais no entorno das unidades de conservação, com a finalidade de incentivar mudanças nas práticas da população local que possam reduzir tanto os impactos humanos sobre a vida silvestre, como os danos da fauna silvestre sobre a produção agropecuária. 
As estratégias de manejo utilizadas para reduzir o impacto causado pela predação são importantes ferramentas para a conservação dos felinos silvestres (Nowell \& Jackson 1996). Utilizar mais de uma estratégia em conjunto pode aumentar a eficiência dos métodos de prevenção (Manzatti 1999). As características peculiares existentes nas comunidades Maria Rosa e Pilões indicam que não são todas as formas/estratégias de manejos de animais domésticos adotadas, ou todas as medidas preventivas sugeridas por diversos pesquisadores que se aplicam nestas áreas.

Para reduzir o conflito entre habitantes e os grandes felinos, têm sido sugerido a criação e manutenção de fundos de indenização financeira específicos para as famílias de comunidades tradicionais residentes em áreas protegidas. Neste sentido, Guix (1997) enviou um manifesto à Secretaria do Meio Ambiente de São Paulo (SMA), com a finalidade de criar um sistema de indenização a proprietários que tiveram suas criações predadas por onças. De forma semelhante, Verdade \& Campos (2004) sugerem que a compensação econômica como medida mitigadora dos conflitos causados pela predação e poderia ser implementada com baixos custos. Na Mata Atlântica, este tipo de estratégia para conservação das onças é uma prioridade, pois o número de onças é pequeno e, conseqüentemente, a ocorrência de predação também, facilitando a implementação de sistemas deste tipo.

Outras medidas preventivas poderiam reduzir os danos causados por predadores silvestres. Primeiro, o confinamento noturno para as criações mais vulneráveis a predadores e o confinamento sazonal nos períodos em que a predação é mais freqüente. Segundo, manter cães pastores treinados para alertar a presença de onças nas redondezas das propriedades. Terceiro, monitorar a presença ou a ausência de onças e ataques às criações domésticas por meio de um planejamento participativo que contasse com o envolvimento da população residente, tanto na coleta de informações, como no estabelecimento de medidas preventivas. Por fim, juntamente com qualquer uma dessas medidas deve ser realizado um trabalho de educação com a população que reside nas áreas mais preservadas de Mata Atlântica e no entorno das unidades de conservação para esclarecer a respeito da importância de conservação das onças da região. Esta estratégia pode ser bastante eficiente, especialmente, para aquela porcentagem expressiva de residentes que não têm uma opinião formada a respeito do conflito.

As comunidades tradicionais necessitam de alternativas econômicas eficazes e não podem sofrer os prejuízos causados pelas predações por onças. Tais medidas preventivas são importantes ferramentas para evitar as perdas dos proprietários e aumentar as chances de conservação dos grandes felinos.

\section{Agradecimentos}

Ao Conselho de Ensino e Pesquisa (PIBIC-CEPE/PUCSP) pela bolsa de pesquisa concedida e a Benvinda Belem Lopes pelo apoio financeiro. À Fundação Florestal, Parque Estadual Intervales e Associação de Moradores dos Bairros Maria Rosa e Porto dos Pilões, Divisão de Proteção dos Recursos Naturais (DPRN), Instituto de Terras do Estado de São Paulo (ITESP) pelo apoio institucional. A todos os entrevistados e moradores das comunidades Maria Rosa e Porto dos Pilões pela participação na coleta de dados, especialmente, à Antonio Franco de Lima (Seu Trabuco) e José da Guia dos Santos (Zeca). À Kátia Pisciotta, Wagner G. Portilho, Sandra G. Soares, Maria Ignez Maricondi (ITESP), Cristiano T. Trinca, Peter G. Crawshaw Jr., Paulo Inácio K.L. Prado, Eleonore Z.F. Setz, Juan Carlos Guix pela concessão de materiais, sugestões e comentários ao manuscrito. À Renata Pardini e aos assessores da Biota Neotropica pelas valiosas recomendações.

\section{Referências Bibliográficas}

ANDERSON, J.L. 1981. The re-establishment and management of a lion Panthera leo population in Zululand, South Africa. Biol. Cons. 19:107-117.

BEIER, P. 1991. Cougar attacks on humans in the United States and Canada, 1890-1990. Wildl. Soc. Bull. 19:403-412.

CARVALHO, J.C.M., LIMA, P.E. \& GALVÃO, E. 1949. Observações zoológicas e antropológicas na região dos formadores do Xingu. Publ. Avuls. Mus. Nac. Rio de Janeiro 5:1-49.

CAVALCANTI, S.M. 1999. Relatório interno de atendimento à denúncia. Centro Nacional de Pesquisa para a Conservação de Predadores Naturais (CENAP) do Instituto Brasileiro do Meio Ambiente e dos Recursos Naturais Renováveis (IBAMA), Iperó.

CONFORTI, V.L. \& AZEVEDO, F.C.C. 2003. Local perceptions of jaguars (Panthera onca) and pumas (Puma concolor) in the Iguaçu National Park area, south Brazil. Biol. Cons. 111:215-221.

CRAWSHAW JUNIOR, P.G. \& QUIGLEY, H.B. 1984. A ecologia do jaguar ou onça-pintada no Pantanal - Estudos bioecológicos no Pantanal - Parte I. Instituto Brasileiro de Desenvolvimento Florestal (IBDF).

DIÁRIO OFICIAL DO ESTADO. 1998. Justiça e defesa da cidadania. Instituto de Terras. D.O.E., Poder Exec., Séc. I, S. Paulo 108(217):3-9.

FOERSTER, C. 1996. Researcher attacked by puma in Corcovado National Park, Costa Rica. Vida Silvestre Neotrop. 5:57-58.

FUNDAÇÃO FLORESTAL, 1997. Parque Estadual Intervales. Plano de Gestão Ambiental, fase I. Fundação para a Conservação e a Produção Florestal do Estado de São Paulo, SMA, São Paulo.

GUIX, J.C. 1997. Cat communities in six areas of the state of São Paulo, southeastern Brazil, with observations on their feeding habits. Grupo de Estud. Ecol., Ser. Doc. 5:16-38.

HEMSON, G. 2003. The ecology and conservation of lions: human-wildlife conflict in semi-arid Botswana. Thesis (PhD), University of Oxford.

HOOGESTEIJN, R., HOOGESTEIJN, A. \& MONDOLFI, E. 1993. Jaguar predation vs. conservation: cattle mortality by felines on three ranches in the Venezuelan Llanos. In Mammals as predators (N. Dunstone \& M.L. Gorman, eds.). Proc. Symp. Zool. Soc. Lond. 65:391-407.

JACKSON, P. \& NOWELL, K. 1996. Problems and possible solutions in management of felid predators. Journal Wildl. Research 1:304-314.

JACKSON, R. \& WANGCHUK, R. 2001. Linking snow leopard conservation and people-wildlife conflict resolution: grassroots measures to protect the endangered snow leopard from herder retribution. Endangered Species UPDATE 18:138-141.

LEONEL, C. 2001. Intervales. Fundação para a Conservação e a Produção Florestal do Estado de São Paulo, SMA, São Paulo.

MANZATTI, L. 1999. Predação de animais domésticos e plantações no entorno do Parque Nacional do Iguaçú (PR) - Análise da percepção de fazendeiros e alternativas de manejo. Dissertação de Mestrado, Escola Superior de Agricultura "Luiz de Queiroz" (ESALQ/USP), Piracicaba.

MAZZOLLI, M., GRAIPEL, M.E. \& DUNSTONE, N. 2002. Mountain lion depredation in southern Brazil. Biol. Cons. 105:43-51.

MELO, A.C.G. \& SALAROLI, E.M. 1990. Diagnóstico ambiental e propostas para o desenvolvimento agrícola nos bairros Porto dos Pilões e Maria Rosa. Relatório final. Departamento Estadual de Proteção dos Recursos Naturais (DPRN/SMA), Registro.

MICHALSKI, F., BOULHOSA, R.L.P., FARIA, A. \& PERES, C.A. 2006 Human-wildlife conflicts in a fragmented Amazonian forest landscape: determinants of large felid depredation on livestock. Animal Cons. 9(2):179-188.

MITTERMEIER, R.A., MYERS, N., GIL, P.R. \& MITTERMEIER, C.G. 1999. Hots Pots: earth's biologically richest and most endangered terrestrial ecorregions. CEMEX/Conservation International, México City.

MIZUTANI, F. 1993. Home range of leopards and their impact on livestock on Kenya ranches. In Mammals as predators (N. Dunstone \& M.L. Gorman, eds.). Proc. Symp. Zool. Soc. Lond. 65:425-439. 
NOWELL, K. \& JACKSON, P. 1996. Wild cats. Status Survey and Conservation Action Plan. IUCN/SSC Cat Specialist Group, Gland, Switzerland.

OLI, M.K., TAYLOR, I.R. \& RODGERS, M.E. 1994. Snow leopard Panthera uncia predation of livestock: an assessment of local perceptions in the Annapurna Conservation Area, Nepal. Biol. Cons. 68:63-68.

PALMEIRA, F.B.L. 2004. Predação de bovinos por onças em propriedades rurais no Norte do Estado de Goiás. Dissertação de Mestrado, Escola Superior de Agricultura "Luiz de Queiroz" (ESALQ/USP), Piracicaba.

PATTERSON, B.D., KASIKI, S.M., SELEMPO, E. \& KAYS, R.W. 2004. Livestock predation by lions (Panthera leo) and others carnivores on ranches neighboring Tsavo National Parks, Kenya. Biol. Cons. 119:507-516

PEROVIC, P.G. \& HERRÁN, M. 1998. Distribución del jaguar Panthera onca en las Provincias de Jujuy y Salta, Noroeste de Argentina. Mastozool. Neotrop. 5(1):47-52.

POLISAR, J., MATIX, I., SCOGNAMILLO, D., FARRELL, L., SUNQUIST, M.E. \& EISENBERG, J.F. 2003. Jaguars, pumas, their prey base, and cattle ranching: ecological interpretations of a management problem. Biol. Cons. 109:297-310.

RABINOWITZ, A.R. 1986. Jaguar predation on domestic livestock in Belize. Wildl. Soc. Bull. 14:170-174.

RAU, J.R. \& JIMÉNEZ, J.E. 2002. Diet of puma (Puma concolor, Carnivore: Felidae) in coastal and Andean ranges of South Chile. Studies on Neotrop. Fauna and Environment 37:201-205.

ROBEL, R.J., DAYTON, A.D., HENDERSON, F.R., MEDUNA, R.L. \& SPAETH, C.W. 1981. Relationships between husbandry methods and sheep losses canine predators. J. Wild. Manage. 45(4):894-911.

RYLANDS, A.B., SILVA, J.A.S., CALAÇA, P.F., SÁBATO, M.A..L. \& OLIVEIRA, L.C. 1995. Monitoramento de felinos predadores de animais domésticos no estado de Minas Gerais, com ênfase no Vale do Rio Doce. Relatório apresentado ao Instituto Estadual de Florestas \& Universidade Federal de Minas Gerais, Belo Horizonte.

SANDERSON, E.W., CHETKIEWICZ, C.L.B., RABINOWITZ, A., REDFORD, K.H., ROBINSON, J.G. \& TABER, A.B. 1999. A geographic analysis of the status and distribution of jaguars across the range. In El jaguar en el nuevo milenio. Una evaluación de su estado, detección de prioridades y recomendaciones para la conservación de los jaguares en America. Mexico (R.A. Medellin, C.L.B. Chetkiewicz, A. Rabinowitz, K.H. Redford, J.G. Robinson, E.W. Sanderson \& A.B. Taber, eds). Universidad Nacional Autónoma de México/Wildlife Conservation Society.

SCHAEFER, J.M., ANDREWS, R.D. \& DINSMORE, J.J. 1981. An assessment of coyote and dog predation on sheep in southern Iowa. J. Wildl. Manage. 45(4):883-893.

SCHALLER, G.B. 1983. Mammals and their biomass on a Brazilian ranch. Arq. Zool., S. Paulo 31(1):1-36.
SCHALLER, G.B., JUNRANG, R. \& MINGJIANG, Q. 1988. Status of the snow leopard Panthera uncia in Qinghai and Gansu Provinces, China. Biol. Cons. 45:179-194.

SEIDENSTICKER, J. \& MCDOUGAL, C. 1993. Tiger predatory behaviour, ecology and conservation. In Mammals as predators (N. Dunstone \& M.L. Gorman, eds.). Proc. Symp. Zool. Soc. Lond. 65:105-125.

SICK, H. 1997. Ornitologia brasileira. 2.ed. Nova Fronteira, Rio de Janeiro.

STUCCHI, D. 1998. Relatório técnico-científico parcial sobre os remanescentes das comunidades de quilombos do Vale do Ribeira, São Paulo.

VERDADE, L.M. \& CAMPOS, C.B. 2004. How much is a puma worth? Economic compensation as an alternative for the conflict between wildlife conservation and livestock production in Brazil. Biota Neotrop. 4(2): http://www.biotaneotropica.org.br/v4n2/pt/abstract?short-communicati on+BN02204022004

VILLAS-BÔAS, C. \& VILLAS-BÔAS, O. 1995. A marcha para o oeste. Editora Globo, São Paulo.

ZAR, F.H. 1996. Biostatistical Analysis. 3.ed. Prentice Hall, Upper Saddle River.

ZIMMERMANN, A., WALPOLE, M.J. \& LEADER-WILLIANS, N. 2005. Cattle ranchers' attitudes to conflicts with jaguar Panthera onca in the Pantanal of Brazil. Oryx 39(4):406-412.

Título: Conflitos causados pela predação de rebanhos domésticos por grandes felinos em comunidades quilombolas na Mata Atlântica.

Autores: Palmeira, FBL e Barrella, W

Biota Neotropica, Vol.7 (número 1): 2007

http://www.biotaneotropica.org.br/v7n1/pt/abstract?article+ bn03707012007

Recebido em 20/06/06 - Versão reformulada recebida em 06/02/07 - Publicado em 31/03/07

ISSN 1676-0603 